\title{
Breast Cancer Awareness Month: The Impact of Even the Most Successful Campaigns Fades
}

Frédéric Lapostolle ( $\nabla$ frederic.lapostolle@aphp.fr)

Assistance Publique - Hopitaux de Paris https://orcid.org/0000-0002-6624-6658

Lisa Weisslinger

Assistance Publique - Hopitaux de Paris

Charles Durand

Assistance Publique - Hopitaux de Paris

Frédéric Adnet

Assistance Publique - Hopitaux de Paris

Research article

Keywords: Breast Cancer, increase public, campaigns fades

Posted Date: July 21st, 2020

DOl: https://doi.org/10.21203/rs.3.rs-44816/v1

License: (9) This work is licensed under a Creative Commons Attribution 4.0 International License.

Read Full License 


\section{Abstract}

\section{Background}

For over 35 years the 'Breast Cancer Awareness Month' (BCAM) has worked to increase public information about breast cancer and to raise funds for research. The aim of this study was to analyze how the interest generated by this campaign evolved over time, in the US and other countries.

\section{Methods}

We investigated the Google Trends ${ }^{\circledR}$ according to previously recommended methods. The study was based on Internet searches using the term "breast cancer" worldwide and in the United-States. Google Trends $\AA$ gives the relative search volume of every request as an index on a scale from 0 to 100 , (100 corresponding to the maximum number of requests during the studied period). We compared the relative searches index using the term "breast cancer" during October, the breast cancer awareness month, and the rest of the of the year avec a 10 years period.

\section{Results}

120 months were analyzed including 10 October months. Median index for worldwide searches on "breast cancer" during the 110 months was 35 (34-39). It didn't significantly change during the study period $\left(R^{2}=0,3\right.$ ). Median index of the 10 peaks was 83 (64-92) ( $p<0,001$ vs 110 months). The peak index linearly decreased $\left(R^{2}=0,88\right)$ during the study period. It reached 100 in 2012 and 64 in 2020.

In the United-States, median index for searches during the 110 months was 28 (26-32). It didn't significantly change during the study period $\left(R^{2}=0,3\right)$. Median index of the 10 peaks was $83(63-92)$ ( $p<0,001$ vs 110 months). The peak index linearly decreased $\left(R^{2}=0,73\right)$ during the study period. It reached 100 in 2012 and 64 in 2020.

\section{Conclusions}

This internet activity study shows that the impact of the 'Breast Cancer Awareness Month' seems to be slowly decreasing. The number of Internet searches generated by the campaign has been reduced by almost $40 \%$ in both the United-States and worldwide.

\section{Introduction}

For over 35 years the 'Breast Cancer Awareness Month' (BCAM) has worked to increase public information about breast cancer and to raise funds for research.(1) This public awareness campaign started in the US but has become largely international. It was shown to be responsible for an increase in the number of mammograms and early detection of breast cancer.(2) It was also proven that the campaign for breast cancer awareness was more effective than those for lung or prostate cancer 
awareness. (3) The authors demonstrated this by analyzing internet searches, further demonstrating that today the internet constitutes an important tool for public information as well as research and sanitary surveillance. It has for example been used to reveal the seasonality of certain diseases, (4) and more recently to analyze people's behavior during the COVID-19 epidemic.(5) A number of studies in different countries have used this tool to evaluate the impact of educational campaigns about cancer.(6-9) The aim of this study was to analyze how the interest generated by an educational campaign about cancer evolved over time, in the US and other countries.

\section{Methods}

We investigated the Google Trends ${ }^{\circledR}$ according to previously recommended methods.(10) The study was based on worldwide Internet searches using the term "breast cancer" without any exclusion criteria. It was our primary end-point. A second analysis focused on the United-States was performed. It was our secondary end-point. Google Trends ${ }^{\circledR}$ gives the relative search volume of every request as an index on a scale from 0 to 100, 100 corresponding to the maximum number of requests during the period of interest. We compared the relative searches index using the term "breast cancer" during October, the breast cancer awareness month, and the rest of the of the year. For this comparison we used a Student's $T$ test. A value of $p<0,05$ was considered as significant. The evolution of the index was studied calculating the Pearson's correlation coefficient $\left(R^{2}\right)$. Correlation was considered strong if $R^{2}$ was greater than 0.6 and very strong if $\mathrm{R}^{2}$ was greater than 0.8.(14) The strength of the relation between the campaign and the public searches was assessed by studying researches related to "breast cancer" (See methods details in the supplementary file). A ten-year period was studied, from June 2010 to June 2020 . This study was performed between the $1^{\text {st }}$ and the $5^{\text {th }}$ July 2020. Results are expressed as median (IQ).

\section{Results}

120 months were analyzed including 10 October months. Median index for worldwide searches on "breast cancer" during the 110 months was 35 (34-39) (Figure). The index never exceeded 50. It didn't significantly change during the study period $\left(R^{2}=0,3\right)$. Median index peaked in October 2010. Median index of the 10 peaks was 83 (64-92) ( $p<0,001$ vs 110 months). The peak index linearly decreased $\left(R^{2}=0,88\right)$ during the study period. It reached 100 in 2012 and 64 in 2020.

In the United-States, median index for searches during the 110 months was 28 (26-32) (Figure). The index never exceeded 39. It didn't significantly change during the study period $\left(R^{2}=0,3\right)$. Median index peaked in October 2010. Median index of the 10 peaks was 83 (63-92) ( $p<0,001$ vs 110 months). The peak index linearly decreased $\left(R^{2}=0,73\right)$ during the study period. It reached 100 in 2012 and 64 in 2020.

For both worldwide and US analysis, the ten first related searches were correlated to breast cancer (Tables Annexes). 


\section{Discussion}

This internet activity study shows that the impact of the 'Breast Cancer Awareness Month' seems to be slowly decreasing. The number of Internet searches generated by the campaign has been reduced by almost $40 \%$ in both the United-States and worldwide. This is preoccupying as the campaign was shown to be linked to a significant improvement in the management of breast cancer. $(2,3)$ It contributed to increasing the number of mammograms performed as well as early diagnosis of breast cancer. A fading of the impact of the 'Breast Cancer Awareness Month' has been previously suggested.(11) This strongly contrasts with the increasing number of organizations and countries involved in this campaign. The WHO promote the campaign worldwide.(https://www.who.int/cancer/events/breast_cancer_month/en/) Many actions such as painting the White House, the Sydney Opera House or the Eiffel Tower in pink or wearing a pink ribbon also promote the campaign.

The main limitation of this study is that these results don't inform us on how this impact women's health. Nevertheless, Internet activity is a strong enough warning to consider this evolution as an alert signal. Physicians involved in breast cancer management and prevention have to be aware of this recent evolution.

\section{Declarations}

- Ethics approval and consent to participate: not applicable

- Consent for publication: OK

- Availability of data and materials: Yes

- Competing interests: None

- Funding: None

- Authors' contributions

- FL \& FA : study design

- FL \& CD : data management and analysis

- FL \& LW : redaction

- Acknowledgements: None

\section{References}

1. Breast Cancer Awareness Month [Internet]. National Breast Cancer Foundation. [cited 2020 Jun 25]. Available from: https://www.nationalbreastcancer.org/breast-cancer-awareness-month

2. Stat Bite: Effect of Breast Cancer Awareness Month on Mammography Use. JNCl J Natl Cancer Inst. 2005 Oct 19;97(20):1493-1493. 
3. Glynn RW, Kelly JC, Coffey N, Sweeney KJ, Kerin MJ. The effect of breast cancer awareness month on internet search activity - a comparison with awareness campaigns for lung and prostate cancer. BMC Cancer. 2011 Oct 12;11:442.

4. Moccia M, Palladino R, Falco A, Saccà F, Lanzillo R, Brescia Morra V. Google Trends: new evidence for seasonality of multiple sclerosis. J Neurol Neurosurg Psychiatry. 2016;87(9):1028-9.

5. Husnayain A, Fuad A, Su EC-Y. Applications of Google Search Trends for risk communication in infectious disease management: A case study of the COVID-19 outbreak in Taiwan. Int J Infect Dis IJID Off Publ Int Soc Infect Dis. 2020 Mar 12;95:221-3.

6. Quintanilha LF, Souza LN, Sanches D, Demarco RS, Fukutani KF. The impact of cancer campaigns in Brazil: a Google Trends analysis. Ecancermedicalscience. 2019;13:963.

7. Mohamad M, Kok HS. Using Google Trends Data to Study Public Interest in Breast Cancer Screening in Malaysia. Asian Pac J Cancer Prev APJCP. 2019 May 25;20(5):1427-32.

8. Schootman M, Toor A, Cavazos-Rehg P, Jeffe DB, McQueen A, Eberth J, et al. The utility of Google Trends data to examine interest in cancer screening. BMJ Open. 2015 Jun 8;5(6):e006678.

9. Foroughi F, Lam AK-Y, Lim MSC, Saremi N, Ahmadvand A. "Googling” for Cancer: An Infodemiological Assessment of Online Search Interests in Australia, Canada, New Zealand, the United Kingdom, and the United States. JMIR Cancer [Internet]. 2016 May 4 [cited 2020 Jun 25];2(1). Available from: https://www.ncbi.nlm.nih.gov/pmc/articles/PMC5369660/

10. Nuti SV, Wayda B, Ranasinghe I, Wang S, Dreyer RP, Chen SI, et al. The use of google trends in health care research: a systematic review. PloS One. 2014;9(10):e109583.

11. Jacobsen GD, Jacobsen KH. Health awareness campaigns and diagnosis rates: Evidence from National Breast Cancer Awareness Month. J Health Econ. 2011 Jan 1;30(1):55-61.

\section{Tables}


Table 1 (Annexes): Ten first associated researches

\begin{tabular}{|ll|}
\hline Worldwide & United-States \\
\hline breast cancer symptoms & breast cancer awareness \\
\hline cancer symptoms & breast cancer symptoms \\
\hline breast cancer awareness & what is breast cancer \\
\hline what is breast cancer & breast cancer month \\
\hline breast cancer treatment & breast cancer walk \\
\hline breast cancer signs & breast cancer signs \\
\hline symptoms of breast cancer & breast cancer treatment \\
\hline signs breast cancer & breast cancer awareness month \\
\hline breast pain & pink breast cancer \\
\hline breast cancer month & breast cancer ribbon \\
\hline
\end{tabular}

Table 2 (Annexes): Ten first countries for 'breast cancer" researches and index

\begin{tabular}{|l|}
\hline Worldwide \\
\hline Jamaica: 100 \\
\hline United-States: 88 \\
\hline Australia: 72 \\
\hline United-Kingdom: 68 \\
\hline Nouvelle-Zélande: 67 \\
\hline Nigeria: 67 \\
\hline Ireland: 63 \\
\hline Philippines: 62 \\
\hline Canada: 61 \\
\hline
\end{tabular}


Figures

$\underline{A}$

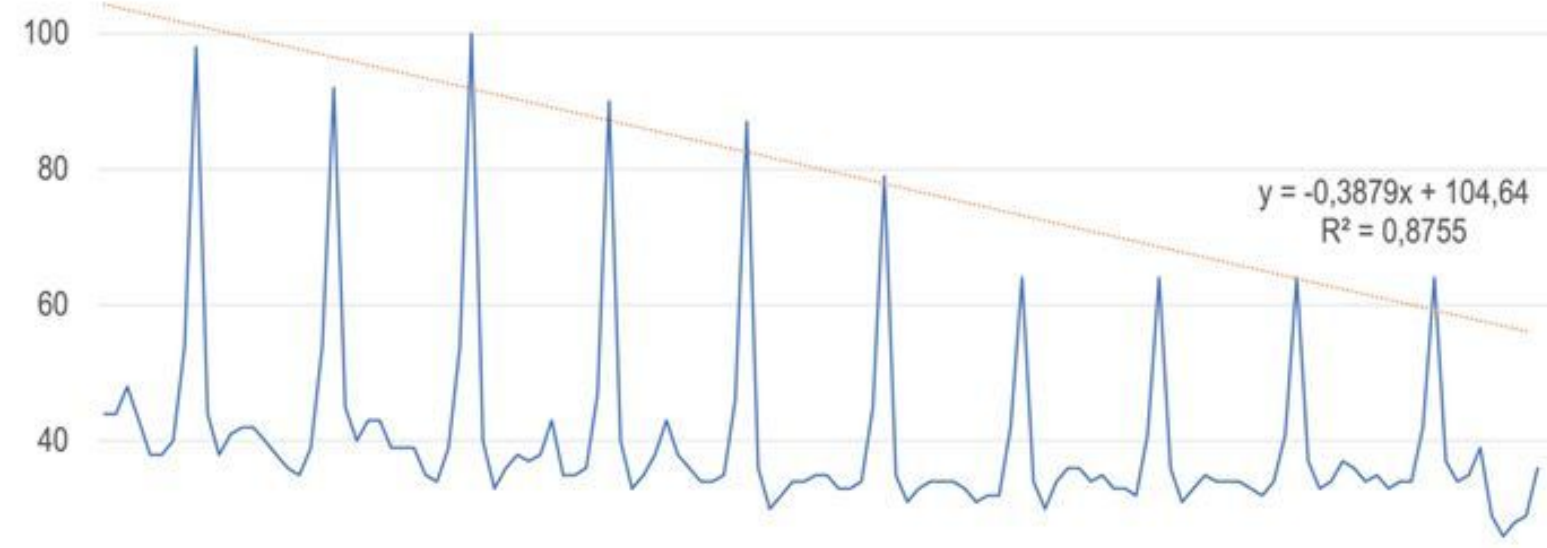

20

0

$\begin{array}{llllllllll}2010 & 2011 & 2012 & 2013 & 2014 & 2015 & 2016 & 2017 & 2018 & 2019\end{array}$

$\underline{B}$

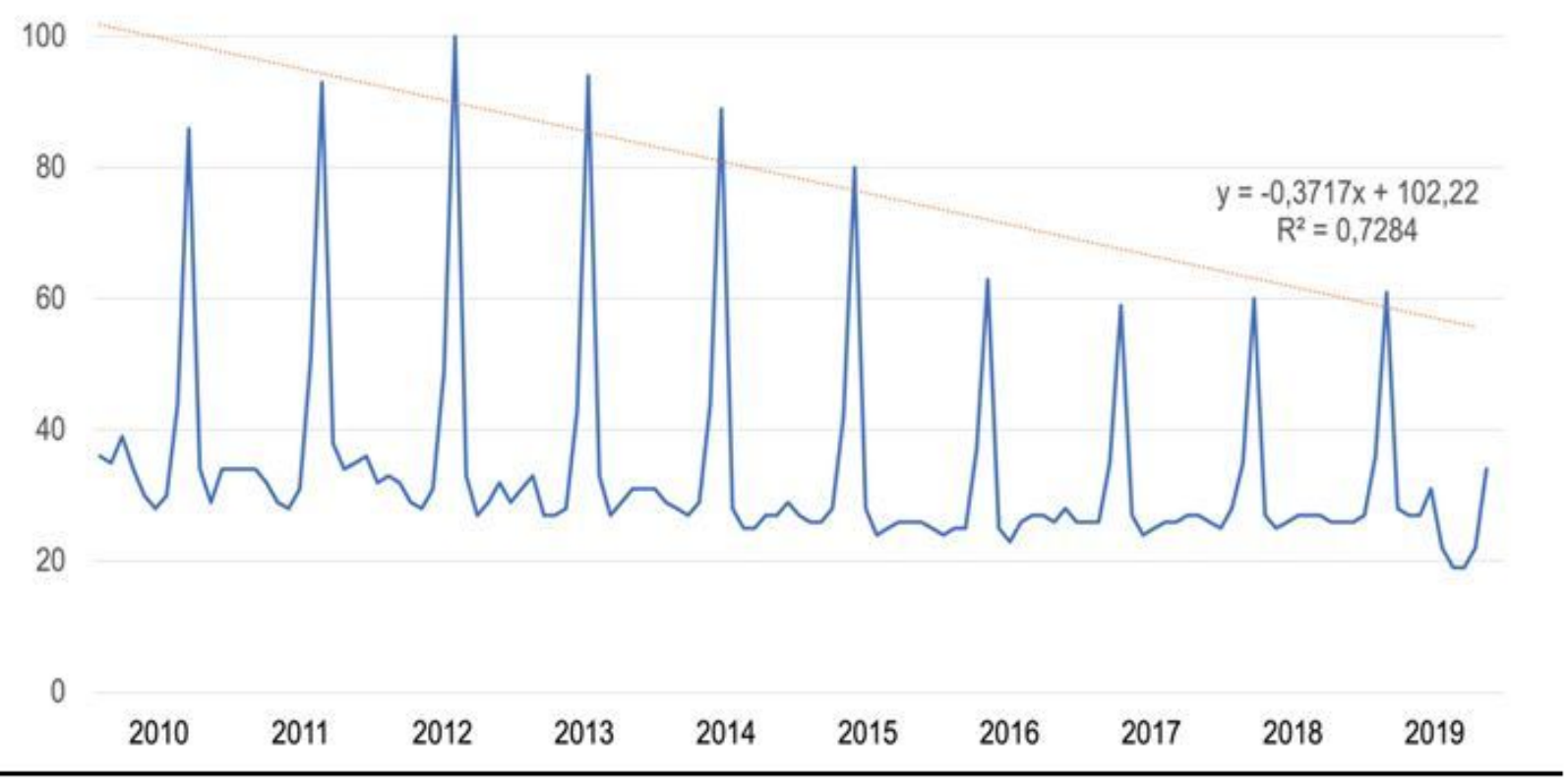

Figure 1

Evolution of worldwide (A) and in the United-States (B) Internet researches for 'breast cancer' during the last 10 years. The orange line indicate the trends for October searches over the studied period. 